\title{
Tropas realistas en la Araucanía durante la Guerra a Muerte (1819-1824): un espacio de movilización indígena y popular
}

\author{
Royalist's Troops in the Araucanía during the War to Death \\ (1819-1824): An Indigenous and Popular Movement Space
}

\author{
Emilia Riquelme Cortés \\ Instituto de Historia Argentina y Americana «Dr. Emilio Ravignani» \\ Universidad de Buenos Aires/Conicet
}

\section{DOI: https://doi.org/10.25032/crh.v6i11.5 \\ Recibido: 2/10/2020 \\ Aceptado: 22/10/2020}

Resumen. Este artículo analiza la movilización de los cuerpos militares del bando realista que se desarrolló en la frontera de la Araucanía durante el período que la historiografía chilena ha denominado Guerra a Muerte (1819-1824). La hipótesis sostiene que esta movilización puede ser pensada como un espacio de acción política que se articuló para rechazar la ofensiva patriota, el cual favoreció la aparición de liderazgos populares - como Vicente Benavides y los hermanos Pincheira-y la masiva incorporación de parcialidades indígenas al conflicto producto del traslado de la guerra a sus territorios. Analizar la composición de los cuerpos militares realistas evidencia que estos fueron cada vez más diversos en su conformación incorporando partidas indígenas, partidas de formación mixta, milicias, cuerpos veteranos y otros de reciente formación. Para abordar el tema se trabajará sobre fuentes primarias entre las que se encuentran partes militares, causas criminales, así como también diversas comunicaciones entre autoridades realistas.

Palabras clave: Realismo popular ; Guerra a muerte; Indígenas; Araucanía

Abstract. The following article analyzes the military corps mobilization from the
Royalist side, which was carried out on the Araucanian border at a time that Chilean
historiography refers to as War to Death (Guerra a Muerte) (1819-1824). Hypothesis
states that this mobilization may be planned as a space of political action articulated in 
organized resistance to reject the patriot offensive, which afforded appearance of popular leaderships - such as Vicente Benavides and The Pincheira Brothers - as the war moved further into aboriginal territories, there was a massive addition of indigenous factions into the conflict. Analysis from the Royalist's military corps, shows that their diversity grew with the addition of indigenous and mix-race factions, veteran corps, and other newly formed corps. It works with primary sources, including military parties, criminal cases and various communications between royalist authorities.

Key words: Popular royalism; War to death; Indigenous; Araucanía

\section{Introducción}

En las últimas décadas, el estudio de los grupos populares y su participación en el período revolucionario en América Latina ha tenido importantes avances y renovaciones. Estas nuevas miradas han puesto en evidencia el componente más político del actuar de estos grupos así como también las diversas formas de participación que tuvieron en las guerras de independencia. Estos debates renovadores tienen un importante punto de partida en la historiografía peruana en la década de 1970 donde se desarrollaron algunas contribuciones muy controversiales que ponían de manifiesto por ejemplo, la activa movilización de los sectores populares a favor del bando contrarrevolucionario. ${ }^{1}$ En general, los estudios que abordan la participación popular en el bando realista caracterizaban a estos sujetos como «tradicionalistas», «ingenuos» o «engañados» por su participación en defensa de esta opción política (Echeverri 2019).

Sin embargo, nuevas e interesantes visiones han venido a contrastar estas interpretaciones y han puesto de manifiesto que el realismo era una fuerza política que debe considerar un significado histórico y un contexto determinado. Por una parte, Marcela Echeverri (2018) que ha estudiado las colectividades de esclavos y grupos indígenas en la actual Colombia da cuenta que el realismo no era algo estático, sino que debe entenderse dentro de su contexto. Por ello, plantea que, contrario de las

\footnotetext{
${ }^{1}$ Véase Raúl Fradkin (ed.). ¿Y el pueblo dónde está? Contribuciones para una historia popular de la Revolución de Independencia en el Río de la Plata. (Buenos Aires: Prometeo libros, 2015), 19. El debate en Heraclio Bonilla y Karen Spalding (comps.). La independencia del Perú. (Lima, Instituto de Estudios Peruanos, 1973)
} 
interpretaciones que caracterizan a los sujetos realistas como colectividades que buscaban restaurar el viejo orden colonial, estático y conservador, en realidad lo que hay que hacer es intentar comprender los significados históricos del realismo y entender el tejido de alianzas multiétnicas que le dan forma, para lo cual es indispensable superar esa caracterización del realismo como contrarrevolucionario y antirrepublicano. Por la otra, el trabajo de Cecilia Méndez (2014) centrado en Huanta, Perú, constata cómo el uso del discurso realista puede ser utilizado con diferentes connotaciones según los contextos en los que era enunciado. En este sentido, la autora plantea que el monarquismo no debe ser visto solo como una restauración absolutista, sino como una opción más instrumental que ideológica.

En el caso de la historiografía chilena por mucho tiempo se impuso la idea de asociar a quienes luchaban por las reales armas en miradas que los vinculaban con el bandidaje, la cual surgió fundamentalmente de la mano de historiadores decimonónicos como Benjamín Vicuña Mackenna (1868) y Diego Barros Arana (1850) y fue transmitiéndose y teniendo peso en la historiografía posterior que repitió las mismas caracterizaciones al referirse a estos sujetos. Mas contemporáneo, un estudio de Ana María Contador analizó a la guerrilla liderada por los hermanos Pincheira basándose en el modelo del bandolerismo social propuesto por Eric Hobsbawm planteando que «la guerrilla campesina de los hermanos Pincheira era expresión de la unión de bandidaje y guerrilla como manifestación de bandidaje social revolucionario de corte tradicionalista» (11). Aunque interesante, el estudio de Contador «encaja» el modelo de Hobsbawm a una realidad completamente distinta y además, tilda de «tradicionalista» este tipo de bandolerismo por invocar al rey, lo cual no necesariamente fue así.

Estudios más actuales como los desarrollados por Leonardo León (2011) y Manuel Pérez (2014 y 2018) han renovado sus miradas sobre estos sujetos abordándolos desde ópticas que plantean que luchaban por mantener su autonomía y que llevaban adelante una guerra por sus propios intereses, dejando en un segundo plano la vinculación de estos sujetos con el realismo. En contraste a lo planteado por León acerca de Vicente Benavides, he planteado en otro trabajo que, si bien no es posible aseverar su convicción absoluta con el realismo, sí se puede indicar que sus acciones tienden a preferir la defensa de esta opción incluso en momentos complejos de la guerra (2017). 
El trabajo de Pérez ha aportado muchísimo al estudio de los Pincheira, pero su principal foco de análisis se centra en el último período de movilizacion de la montonera realista y no analiza en profundidad la Guerra a Muerte, además que no considera las discusiones en torno al realismo, que es necesario tener en cuenta a la luz de su planteamiento sobre el alineamiento político de la montonera al que considera como un espacio de autonomía. Al igual que el estudio de Contador citado anteriormente, el trabajo de Pérez carece de atención a la coalición con parcialidades indígenas a ambos lados de la cordillera, siendo analizadas de manera general, sin atender a los conflictos entre lonkos ${ }^{2}$ fundamentales para comprender su vinculación a los bandos en disputa. 3

Sobre este último tema, los trabajos de José Bengoa (1996) y Jorge Pinto (2003) han puesto de manifiesto los conflictos entre los indígenas principalmente en la zona de la Araucanía. Aunque no han trabajado particularmente sobre el período abordado en este trabajo, ambos autores dejan entrever que consideran la participación indígena en la guerra de independencia como distante y asociada a sus propios intereses. Estudios más recientes han demostrado que los indígenas que se involucraron en la «Guerra a Muerte» lo hicieron llevando adelante su propia agencia lo cual no había sido destacado por los trabajos anteriores. El trabajo de Joanna Crow y Juan Luis Ossa aborda la participación político-militar mapuche en este período planteando que en las negociaciones que se desarrollaron «las comunidades mapuches actuaron portando una sofisticada agencia política, y no como actores supuestamente 'manipulados' por las autoridades realistas o revolucionarias» (39). A su vez, Fernando Pairicán destaca el impacto de la Guerra a Muerte en la sociedad indígena, pues aunque este enfrentamiento era parte del binomio patriotas versus realistas las parcialidades que se sumaron también tenían «permanentes pugnas, alianzas y contraalianzas» (69), lo

\footnotetext{
${ }^{2}$ Lonko es el nombre recibido por los caciques mapuche.

3 La historiografía argentina ha estudiado a estos sujetos pero poniendo mayor énfasis en Pincheira y sus aliados indígenas en las pampas. Véase: Daniel Villar y Juan Francisco Jiménez. «Conflicto, poder y justicia. El cacique Martín Toriano en la cordillera y las pampas (1818-1832)». Conflicto, poder y justicia en la frontera bonaerense, 1818-1832. Daniel Villar, Juan Francisco Jiménez y Silvia Ratto. (Bahía Blanca \& Santa Rosa: Departamento de Humanidades de la Universidad Nacional del Sur y Facultad de Ciencias Humanas de la Universidad Nacional de La Pampa, 2003), 131-286; Juan Francisco Jiménez. «De malares y armas de fuego. Guerras intra-étnicas y transformaciones en la tecnología bélica en Araucanía y las Pampas (1818-1830)». Relaciones inter-étnicas en el Sur bonaerense 1810-1830. Daniel Villar (ed.). (Bahía Blanca: Departamento de Humanidades, Universidad Nacional del Sur/IEHS, Universidad Nacional del Centro de la Provincia de Buenos Aires, 1998), 47-78; Carla Manara. «Movilización en las fronteras. Los Pincheira y el último intento de reconquista hispana en el sur americano (1818-1832)», Sociedades de paisajes áridos y semiáridos 2 (2010): 39-60.
} 
cual obligó a las autoridades de ambos bandos a negociar con ellas con el fin de obtener su apoyo y lealtad. En este contexto, en apoyo a los realistas destacó el liderazgo del cacique Mariluan que evidenció la existencia de una agencia indígena que aprovechó el contexto de la guerra para afianzar su poder o dirimir sus propios conflictos (Paircán 91). El liderazgo de Mariluan ha sido estudiado por Rodrigo Araya (2003) que cuestionando las visiones historiográficas sobre este cacique ha destacado el importante rol que jugó durante la Guerra a Muerte.

Los anteriores planteamientos de la historiografía chilena si bien han sido un aporte que ha permitido avanzar en el estudio de los sujetos involucrados en la movilización realista durante la «Guerra a Muerte» han analizado a estos sujetos como entidades separadas, dando cuenta de manera superficial de las vinculaciones entre quienes defendieron el realismo. Por otro lado, los estudios centrados en los liderazgos realistas, como los de Pérez, aunque han aportado muchos elementos interesantes para la discusión, no han considerado los estudios sobre el realismo popular que permitirían pensar la vinculación al realismo como un fenómeno cambiante que pudo ser parte de una estrategia que involucraba la acción política de los sujetos que adherían a él, lo cual incluso posibilitó que en nombre del rey se generaran importantes cambios favorables a los grupos populares (Echeverri 2018).

Las propuestas sobre el realismo popular han favorecido que se pueda analizar a los defensores del realismo desde ópticas nuevas que consideren tanto la importancia del contexto como los diversos significados que los sujetos pudieron entregar al realismo que defendían. Es justamente en estas nuevas ópticas que se inserta el presente artículo, el cual tiene como objetivo analizar la movilización de los cuerpos militares que lucharon por el bando realista en el actual territorio chileno, específicamente en la zona de la Araucanía, donde los realistas se refugiaron tras su derrota en la Batalla de Maipú en abril de 1818. Esta movilización que la historiografía decimonónica chilena denominó Guerra a Muerte se extendió hasta 1824 y contó con el apoyo de un grupo heterogéneo de sujetos, provenientes de diferentes estratos sociales y tuvo entre sus principales liderazgos a Vicente Benavides y Antonio Pincheira. A su vez, la alianza con el cacique Mariluan fue fundamental para definir en ciertos momentos la correlación de fuerzas en la zona. 
Por lo tanto, nos interesa pensar la movilización realista ${ }^{4}$ sobre base de las nuevas miradas que se ha dado al realismo entendiendo que la vinculación de estos sujetos y sus seguidores con la causa realista fue parte de una acción política que no puede pensarse solo como ingenua o meramente instrumental. Se plantea como hipótesis que esta movilización puede ser pensada como un espacio de acción política que se organizó sobre la base de diversos cuerpos militares -partidas indígenas, partidas de formación mixta, milicias, cuerpos veteranos y otros de reciente formación - para rechazar la ofensiva patriota y que este espacio de acción favoreció que sujetos de diferentes procedencias étnicas, defendiendo el realismo, pudieran acceder tanto a movilidad social como también conseguir apoyo para dirimir sus propios conflictos para lo cual utilizaron prácticas que tenían cierto arraigo entre estos sujetos como eran las formas de negociación de los indígenas con las autoridades así como también los méritos en acciones bélicas para conseguir ascensos y reconocimientos.

A su vez, esta acción política favoreció la aparición de liderazgos populares 5 como Vicente Benavides y los hermanos Pincheira - además de la importante alianza e incorporación de parcialidades indígenas al conflicto producto del traslado de la guerra a sus territorios, entre las cuales destacan las lideradas por el cacique Mariluan. ${ }^{6}$ Para abordar el tema se trabajará sobre diversas fuentes primarias entre las que se encuentran partes militares y comunicaciones varias, así como también la causa criminal contra Vicente Benavides.

Para mayor claridad, el artículo comprende tres apartados. El primero de ellos contextualiza la Guerra a Muerte y explica cómo se configuró la movilización realista

\footnotetext{
4 En este artículo la categoría realistas se usa en referencia a sujetos y grupos que se movilizaron invocando el nombre del rey.

5 Se entiende el liderazgo en un sentido amplio, considerando que este se ejerce cuando una persona es capaz de influir, organizar y llevar adelante acciones con un determinado fin involucrando a otros sujetos en dichas acciones. Al hablar de liderazgos populares se hace referencia a sujetos que cumplían con estas características pero que no provenían de la elite. En el caso de los liderazgos indígenas, estos refieren a los caciques que poseen el control de ciertos espacios territoriales autónomos.

${ }^{6}$ El uso de los términos «popular» e «indígena» de manera separada obedece a una decisión metodológica que busca dar cuenta de sujetos que se encontraban en distinta posición en el orden colonial. En efecto, los sujetos populares a los que se hace referencia ostentaban una condición de subalternidad al orden colonial, mientras que las parcialidades indígenas referidas eran autónomas, mantenían sus liderazgos, control de territorios y por tanto, es discutible poder referirse a ellas como subalternos. De todos modos, resulta importante señalar que al utilizar los términos popular e indígena no se está pensando en estos como categorías fijas, sino que responden más bien a categorías analíticas propuestas con el fin de hacer más comprensible al lector el fenómeno estudiado.
} 
en la Araucanía. En segundo lugar, se analiza la composición de las tropas regulares veteranas y milicianas- que conformaron la movilización realista durante el período y expone las unidades militares existentes, la composición de la oficialidad y el principal liderazgo popular que surgió en su seno: Vicente Benavides. El tercer apartado analiza las partidas indígenas y de formación mixta que se movilizaron invocando el nombre del rey mencionando sus principales liderazgos, forma de ataque, vinculación con las tropas regulares y prácticas de negociación. A modo de cierre se exponen los elementos que permiten dar cuenta que los cuerpos militares movilizados en nombre del rey, por el particular contexto de la guerra, desarrollaron tropas de composición muy diversa, lo cual favoreció que en defensa del realismo diversos sujetos pudieran ascender socialmente, que algunas parcialidades consiguieran apoyo para abordar sus propios conflictos, así como también la aparición de liderazgos populares e indígenas que fueron fundamentales para mantener la movilización activa en la zona.

\section{La guerra se traslada al sur. Movilización realista en la Araucanía durante la Guerra a Muerte (1819-1824)}

Al grito de iViva el Rei! Todo el sur estaba de pie. La Patria no era Chile, era Santiago. Por esto, solo cuando se pacificó completamente el medio-día (1824), la nación tomó oficialmente, $i$ por oficial decreto, el nombre que hasta hoy ha sustentado con orgullo.

Vicuña Mackenna XVIII

A inicios de 1817 tras el cruce del ejército libertador de los Andes y el triunfo en Chacabuco, el 12 de febrero de ese año, los patriotas se apoderaban de Santiago logrando el control de gran parte del territorio central de Chile. El gobernador Francisco Casimiro Marcó del Pont huía a Valparaíso siendo capturado y más tarde enviado a Mendoza. Justo un año después era firmada en Santiago la Declaración de Independencia por el director supremo Bernardo O'Higgins.

A pesar de las implicancias que podía tener la firma de esta declaración, los enfrentamientos entre patriotas y realistas se mantuvieron. Estos últimos lograron un importante triunfo en Cancha Rayada -a $250 \mathrm{~km}$ de Santiago- que por momentos puso en peligro a la capital, pero que luego los patriotas lograron revertir en Maipú el 5 de abril de 1818. De alguna forma, esta batalla selló un proceso que se venía gestando, y es reconocida como una especie de hito que marcó el fin del dominio colonial en el 
territorio chileno. La historiografía ha retomado esta importancia y muestra a Maipú como el sello simbólico del triunfo sobre los realistas. Como mencionan Julio Pinto y Verónica Valdivia: «la batalla de Maipú, si bien no puso fin a una guerra que se prolongaría [...] muchos años más, tuvo el efecto de estabilizar el control político del bando patriota sobre la mayor parte del territorio que se estaba en trance de convertir en nación» (159), lo cual provocó que «a partir de 1818, la insurgencia patriota se convirtió definitivamente en un proyecto de construcción nacional» (Pinto y Valdivia 159).

Aun cuando el triunfo de Maipú fue fundamental para el control del territorio central de Chile los restos dispersos de las tropas realistas se refugiaron, principalmente en la frontera de la Araucanía al sur del río Biobío. En esta zona, habitaba un número importante de parcialidades indígenas que no ostentaban una condición subalterna dentro del orden colonial sino que mantenían sus estructuras, liderazgos y control de territorios lo cual fue fundamental para mantener la movilización. Gran parte de los contingentes de soldados realistas no solo se trasladaron a las ciudades más lejanas a Santiago que seguían en dominio realista como Valdivia y Chiloé, sino que también, muchos se refugiaron en territorio indígena. Ahora bien, ¿̇cómo estos restos dispersos de las tropas lograron organizar la movilización realista en esta zona?

Tras la huida de Marcó del Pont, la tropa realista quedó a cargo del español Mariano Osorio quien luego de la derrota de Maipú huyó a Lima dejando las tropas a cargo del comandante Juan Francisco Sánchez. Este último quedó en Concepción a la espera de recibir auxilios, refuerzos e instrucciones para contener los avances patriotas a cargo del general Antonio González Balcarce. A fines de 1818, y luego de varios meses de enfrentamientos, Sánchez no pudo contener los ataques de los patriotas y tomó la decisión de huir con el resto de sus tropas hacia Valdivia atravesando territorio indígena. La retirada de Sánchez generó entre los patriotas la idea de que la guerra había terminado y que habían salido victoriosos, por lo cual Balcarce -al igual que Sánchez- se retiró de la Provincia de Concepción dejándola en manos de Ramón Freire que asumía la Intendencia en enero de 1819. La prensa de la época no dudó en presumir el triunfo revolucionario y dar por terminada la resistencia en el sur: «La campaña del Sur se ha concluido felizmente, según lo manifiesta el parte que se acaba de recibir del señor brigadier General don Antonio González Balcarce. iHonor y gloria 
a los bravos del ejército del Sur!» (Feliú 58). Estas conclusiones apresuradas de los patriotas terminaron por ser desastrosas y favorecieron la reorganización de las tropas realistas que pronto pasaron de pequeñas escaramuzas a enfrentamientos más grandes.

En febrero de 1819, aunque dispersas tras los eventos de Maipú, estas tropas dieron las primeras muestras claras de su reorganización durante un ataque combinado en varios lugares de la provincia de Concepción dejando atrás las escaramuzas esporádicas e inaugurando una «resistencia formal» contra los patriotas: el margen sur del Biobío era atacado en diferentes puntos como Negrete, Santa Juana y San Pedro: «esto sucedía en la ribera sur del río i casi toda la longitud de su curso» (Vicuña Mackenna 10); al mismo tiempo:

una guerrilla aparecía en la margen boreal del Río por el lado de Talcamávida, frente a Santa Juana; grupo de indios cruzaban el río de la Laja y se dirigían cometiendo horribles depredaciones hacia Rere, a espaldas de Concepción amenazando interceptar esta plaza de la de Chillán (Vicuña Mackenna 10).

Adicionalmente, más al norte hacían su entrada las partidas de formación mixta7 lideradas por Antonio Pincheira que atacaba en compañía de un número importante de indígenas: «en la confluencia del Ñuble con el Itata se presentaban a la cabeza de montoneros de bandidos los guerrilleros Contreras, Fuentes i el feroz Antonio Pincheira» (Vicuña Mackenna 11).

\footnotetext{
$7 \mathrm{Al}$ hablar de «partidas de formación mixta» se ha considerado el término utilizado por Juan Francisco Jiménez que denomina formaciones mixtas a fuerzas compuestas por hispanocriollos y mapuche en las que se combinaban las culturas militares de sus componentes. Se antepone el término «partidas» por su forma de ataque similar a las partidas indígenas, en pequeños grupos que no presentaban enfrentamiento directo. (Véase: Juan Francisco Jiménez: 66). Aunque la denominación "partidas de formación mixta» es polémico, el término es de utilidad para referir a una composición étnica diversa en los ataques y liderazgos. Esto no omite que los límites entre ambos grupos étnicos eran porosos y que, por tanto, no existía una separación étnica estricta.
} 
Mapa 1

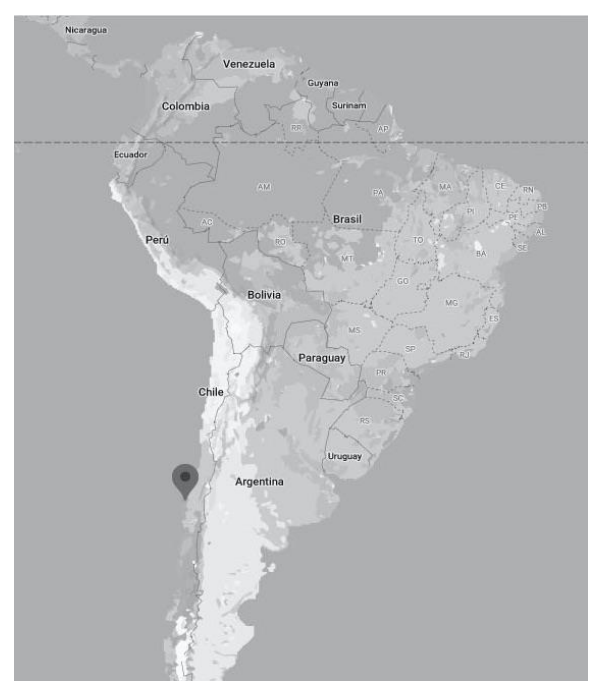

Mapa 2

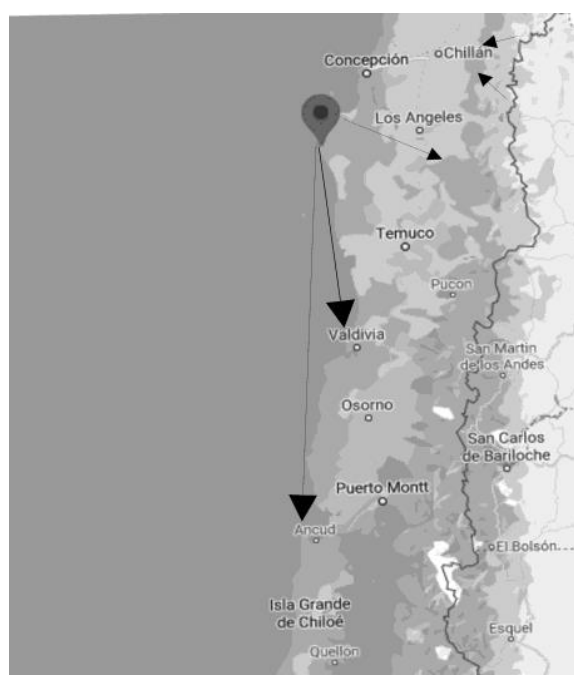

El mapa 1 muestra el punto desde se movilizaban las tropas realistas al sur de Concepción en la localidad de Lebu (ribera sur del río Biobío). El mapa 2 muestra un acercaminto a la zona mostrando que desde Lebu se movilizaba la tropa al sur del río Biobío donde habitaban las parcialidades indígenas aliadas y, a la vez, era el punto desde donde se comunicaban con las ciudades del sur que seguían en dominio realista (Valdivia, San Carlos de Chiloé). Además, se muestra desde la cordillera la movilización de las partidas de formación mixta hacia Chillán y sus alrededores.

El anterior ataque combinado mostró dos elementos fundamentales para comprender las acciones de la movilización realista: por un lado, que desde aquella fecha en adelante la resistencia realista contra los patriotas comenzaría su organización lo cual generó que en varios momentos la guerra estuviera a su favor lo que puso en riesgo la tan anhelada tranquilidad que Santiago hacía alarde tras los sucesos de Maipú; por otro lado, puso en evidencia que esta reorganización contaba con una variedad importante de tropas: cuerpos veteranos a cargo de distintos oficiales, algunas milicias y la acción de las partidas indígenas y de formación mixta. Cabe destacar que, aunque en ocasiones actuaran como fuerzas conjuntas, no necesariamente eran fuerzas dependientes, en particular las partidas indígenas y de formación mixta que parecían ser aliados más que un cuerpo sometido jerárquicamente a las tropas regulares.

Estos hechos van a mostrar que los realistas aún no habían sido derrotados y que su reorganización iba a convertirse en un verdadero peligro para las aspiraciones de independencia. Uno de los primeros historiadores que escribió sobre esta 
movilización fue Benjamín Vicuña Mackenna ${ }^{8}$ que utilizó el término «Guerra a Muerte»9 para referirse a este período haciendo un paralelo con lo sucedido en la guerra de Independencia en Venezuela cuando Simón Bolívar a través de un decreto declaraba la guerra a muerte a sus adversarios. Para Vicuña Mackenna, lo sucedido en el sur de Chile había sido similar en particular luego de la reorganización de las tropas realistas y hasta la caída de sus últimos líderes en 1824 ya que, según el autor, Vicente Benavides habría declarado la guerra sin cuartel en una proclama que hizo luego de aquel ataque combinado donde mencionaba que:

deberá fijar por punto principal el destruir al enemigo según i como lo permitan sus fuerzas, persiguiéndolo siempre que pueda hasta su total exterminación, i lo mismo con todo aquel que se le justifique ser adicto i defensor de sus ideas (Vicuña Mackenna 517).

En un primer momento la reorganización realista contó con dos liderazgos populares fundamentales para mantener las acciones bélicas: en los alrededores de Concepción vemos emerger el liderazgo de Vicente Benavides a cargo de la tropa regular; por su parte, en la zona montañosa la actuación de Antonio Pincheira ${ }^{10}$ favoreció la movilización de partidas de formación mixta que actuaban combinadas con las tropas regulares, pero no se sometieron a ellas. En el caso de la movilización de las partidas indígenas destacó fuertemente el liderazgo del cacique Mariluan.

Esta movilización, organizada en variados cuerpos militares y en partidas indígenas y de formación mixta «se inicia con una gran derrota de los patriotas en mano de los hombres que había logrado reunir Benavides y que de armamentos al parecer solo contaban con palos» (Barros Arana 14). En los apartados siguientes, se

\footnotetext{
8 Benjamín Vicuña Mackenna (1831-1886) fue un historiador y político liberal chileno que desarrolló importantes obras historiográficas que generaron más de alguna polémica. Un dato importante para el tema abordado es que siendo diputado por Valdivia impulsó una campaña para la conquista militar de Arauco, y en consonancia con esa preocupación publicó su texto La Guerra a Muerte. Memorias sobre las últimas campañas de la independencia de Chile. 1819-1824 que justamente presenta una mirada sobre los mapuche que buscaba servir de justificación para el avance militar que proponía. Sobre su trabajo historiográfico, Cristian Gazmuri menciona que en él se plasmó con fuerza el uso de la hipérbole: invento lo que no había (o exageró lo que sabía), cayó en contradicciones y creó mitos (2006).

9 Si bien otros autores, como Carla Manara, cuestionan la periodización de la «Guerra a muerte» extendiendo su desarrollo hasta la caída del último de los hermanos Pincheira en 1832 (ver: Manara 2010), nos parece que desde 1825 en adelante estaríamos frente a otro proceso que coincide con el liderazgo de los hermanos menores en la montonera y su movilización hasta la actual Pampa argentina, y por lo tanto, adoptamos la categoría de la «Guerra a muerte» hasta 1824 tal como la planteó Vicuña Mackenna.

${ }^{10}$ Los cuatro hermanos Pincheira se movilizaron asumiendo el mando de estas partidas sucesivamente hasta 1832. Los dos hermanos menores, Pablo y José Antonio, no solo se mantuvieron movilizados hasta este año, sino que ampliaron considerablemente su radio de acción llegando hasta el sur de la provincia de Buenos Aires.
} 
analizarán estos cuerpos militares por separado para obtener una mejor noción de ellos.

\section{Cuerpos veteranos y milicias: composición de la tropa regular realista}

La movilización que se concentró en el borde del río Bíobío estuvo conformada principalmente por las tropas regulares que fueron reorganizadas por Vicente Benavides a inicios de 1819 y que tenían como objetivo la recuperación de Concepción y acceso al puerto de Talcahuano. Acerca de estas se tiene mucha más información en comparación con las partidas indígenas y de formación mixta. Esta información proviene principalmente de la documentación producida por las autoridades realistas durante el período del liderazgo de Benavides. A este respecto, uno de los documentos más valiosos para conocer la composición de las unidades militares es un estado de fuerza hecho en 1820 por Vicente Benavides para el comandante Juan Francisco Sánchez que constantemente requería información sobre las tropas que Benavides tenía a cargo. La tabla 1 entrega un resumen de aquella información:

Tabla 1.

Resumen del número de tropa enunciado en el estado general realizado por Vicente Benavides en 1820

\begin{tabular}{|l|c|}
\hline \multicolumn{1}{|c|}{ Cuerpos veteranos } & Total de tropa \\
\hline Real Cuerpo de Artillería & 46 \\
\hline Regimiento de Infantería montada & 905 \\
\hline Regimiento de Dragones de Nueva Creación & 800 \\
\hline Suma total & 1751 \\
\hline$\quad$ Cuerpos de milicias Disciplinadas y Concordia & Total de tropa \\
\hline Escuadrón de milicias disciplinadas & 2400 \\
\hline Batallón de la Concordia de Concepción & 400 \\
\hline Suma total & 2800 \\
\hline
\end{tabular}

Elaboración propia a partir del Estado General de la fuerza efectiva elaborado por Vicente Benavides, Concepción, nov. 12, 1820. Archivo Nacional Histórico de Chile (ANH), Santiago de Chile, Chile, Fondo Ministerio de Guerra, volumen 52.

De acuerdo con la información de la tabla 1 en 1820 existían tres cuerpos veteranos con 1751 hombres además de dos cuerpos milicianos con 2800 hombres. Si se compara con la tropa movilizada por el ejército libertador de Los Andes podemos observar que, según estos datos, la movilización realista era considerable. Juan Luis Ossa menciona que «San Martín's reforms allowed him to mobilise 5887 men by the end of December 1815» (2014: 38); por su parte, el ejército realista alcanzaba una tropa total de 4551 hombres. Aunque levemente más baja que la tropa del ejército comandado por San Martín, se debe considerar que en esta cuenta no estaban incluídas 
las partidas indígenas y de formación mixta aliadas que sumaban otros cientos de hombres.

Las cifras expuestas por Benavides en el estado de fuerza deben considerarse con cautela, ya que no es posible confiar a plenitud en ellas pues en el contexto que se desarrollaron muchas veces las cifras eran exageradas con distintos fines, como conseguir más auxilios o dar credibilidad a la tropa comandada; a su vez, Barros Arana entrega una cifra mucho menor mencionando que «Benavides estaba al mando de un cuerpo de tropas bastante formidable que contaba con más de 2000 hombres» (Barros Arana 24-25) lo cual hace pensar en una movilización que seguramente sobrepasaba los dos mil hombres armados pero que no superaba los tres mil.

Cabe destacar que, aunque no se conozcan más datos, el anterior recuento de fuerzas no fue el único que hizo Benavides, pues las autoridades que lo auxiliaban constantemente le solicitaban conocer el estado de sus tropas. En 1819, Juan Francisco Sánchez desde Valdivia solicitaba «noticia de quantos individuos se hallan incorporados en la división de su mando». ${ }^{11}$ Una vez que tuvo respuesta de Benavides le contestó lo siguiente:

he recibido el Estado de la Fuerza que vM. tiene en esa Frontera, como los demás documentos relativos a los cuerpos de Infantería y Cavallería de nueva creación que vM. me ha remitido en oficio del 8 del actual a los quedaré el curso correspondiente previniendole, que los oficiales provistos continúen en sus empleos pues todos ellos son de mi aprovación. ${ }^{12}$

El detalle del estado de fuerza y la contestación de Sánchez a Benavides permiten vislumbrar que la movilización realista en la zona estaba estructurada en cuerpos veteranos ya existentes y otros de nueva formación. El nuevo cuerpo militar denominado regimiento de dragones de nueva creación y el de infantería montada tenían una distribución de tropa muy similar estando notoriamente mejor dotados que el real cuerpo de artillería. Junto a ellos, se organizaban los cuerpos de milicias que:

se componían de un cuerpo de Concordia de cuatro compañías con el número de cien hombres cada una, armadas a la lanza, qué hacen el servicio de esta ciudad [Concepción] y

\footnotetext{
${ }^{11}$ Comunicación entre Juan Francisco Sánchez y Vicente Benavides, Valdivia, may. 4, 1819. Archivo Nacional Histórico de Chile (ANH), Santiago de Chile, Chile, Fondo Ministerio de Guerra, volumen 52, foja 25 .

12 Comunicación entre Juan Francisco Sánchez y Vicente Benavides, Valdivia, jun. 26, 1819. ANH, Santiago de Chile, Chile, Fondo Ministerio de Guerra, volumen 52, foja 34.
} 
doce escuadrones de caballería de a doscientos hombres cada uno, con la misma arma, que igualmente se hayan disciplinados y en actual servicio. ${ }^{13}$

Los cuerpos militares descritos por Benavides coincidían con los existentes en la Provincia de Concepción durante las últimas décadas de la época colonial. En su tesis doctoral, Francisco de Almozara (2015) especifica las unidades militares de la provincia detallando nombre, cantidad compañías y año de creación, lo que muestra que existía coherencia entre los cuerpos y unidades existentes y las presentadas por Benavides. Por tanto, es posible que los cuerpos nuevos en realidad reemplazaran a los que existían. Las tablas 2 y 3, que resumen las unidades militares de Concepción a fines del siglo XVIII y las presentadas por Benavides respectivamente, permiten observar con mayor claridad lo mencionado:

Tabla 2

Unidades militares de Concepción a fines del siglo XVIII

\begin{tabular}{|c|c|c|}
\hline $\begin{array}{c}\text { Cuerpos de } \\
\text { Veteranos, Provincia } \\
\text { de Concepción }\end{array}$ & Compañías & Año creación \\
\hline Dragones de la Frontera & 8 Compañías & 1778 \\
\hline Batallón de Infantería & $\begin{array}{c}\text { 1 Compañía de Granaderos y } \\
\text { 8 de Fusileros }\end{array}$ & 1778 \\
\hline $\begin{array}{c}\text { Compañía de Artillería } \\
\text { de La Frontera }\end{array}$ & 1 Compañía & $\begin{array}{c}\text { Creada en 1769 y } \\
\text { reorganizada en 1778 }\end{array}$ \\
\hline $\begin{array}{c}\text { Cuerpos de milicias, } \\
\text { Provincia de } \\
\text { Concepción }\end{array}$ & Compañías creación \\
\hline Batallón de Infantería & 9 Compañías & 1780 \\
\hline Escuadrón de Caballería & 3 Compañías & 1780 \\
\hline
\end{tabular}

Elaboración propia a partir de la información extraída de Francisco de Almozara, «El Ejército de Chile. De la Capitanía General a la joven República (1603-1823)», Tesis de Doctorado en Historia, Madrid: Universidad Carlos III, 2015, 273-79.

\section{Tabla 3}

Resumen de los cuerpos militares descritos en el estado de fuerza presentado por Vicente Benavides en 1820

\begin{tabular}{|c|c|}
\hline Cuerpos veteranos & Compañías \\
\hline Regimiento de Dragones de Nueva Creación & - \\
\hline Regimiento de Infantería montada & - \\
\hline Real Cuerpo de Artillería & - \\
\hline $\begin{array}{c}\text { Cuerpos de milicias Disciplinadas y } \\
\text { Concordia }\end{array}$ & Compañías \\
\hline Escuadrón de milicias disciplinadas & 12 \\
\hline Batallón de la Concordia de Concepción & 4 \\
\hline
\end{tabular}

\footnotetext{
13 Estado General de la fuerza efectiva elaborado por Vicente Benavides, Concepción, nov. 12, 1820. ANH, Santiago de Chile, Chile, Fondo Ministerio de Guerra, volumen 52.
} 
Elaboración propia a partir del Estado General de la fuerza efectiva elaborado por Vicente Benavides, Concepción, nov. 12, 1820. ANH, Santiago de Chile, Chile, Fondo Ministerio de Guerra, volumen 52.

Desde que Benavides asumió el mando de las tropas, estas eran constantemente reforzadas con auxilios, municiones y soldados desde las ciudades cercanas que aún se mantenían en poder de los realistas. Estos auxilios y el contacto con otras autoridades le entregaban a la reorganización comandada por Benavides algún grado de legitimidad para mantener la lucha y atraer soldados a sus filas. En mayo de 1819, Manuel Montoya, intendente de Valdivia, felicitaba a Benavides para que continuara con sus acciones: «por las noticias de su buen comportamiento en la defensa de la justa causa de nuestro soberano, de Dios y de la patria y la felicidad con que prospera cuyo feliz éxito le doy el para bien, deseándole continúe en su acierto como hasta aquí»,14 además de enviar los auxilios requeridos por este: «el señor general, de acuerdo conmigo, se le remite a V. auxilios de 12.000 cartuchos de fusil con bala 500 piedras de chispa, con el dinero y demás artículos que dicho señor detallará».15 Un año más tarde, desde Lima el virrey del Perú, Joaquín de la Pezuela y Sánchez, también enviaba auxilios a Benavides y además daba instrucciones para que desde Chiloé se le siguiera sosteniendo:

con esta fecha prevengo al señor gobernador de Chiloé que de los oficiales, sargentos y cabos sobrantes que existen en aquella plaza le remito a usted sin la menor demora los que pueda y conceptúe capaces de servir en esa divicion; y en cuanto a los demás auxilios que me pide usted en su oficio de 8 de marzo último que ha motibado esta contestacion, me refiero a lo que (sírvase) remisión de algunos artículos le tengo dicho en esta misma oportunidad. 16

Estos auxilios permitieron a las tropas regulares mantener la movilización en la zona, además de dar legitimidad a las acciones de Benavides apoyadas por el mismo virrey Pezuela.

En conclusión, se puede observar que, con algunas variaciones, la movilización realista de la tropa regular se reorganizó principalmente en torno a las unidades militares existentes. La variación más importante se concentró en las tropas veteranas

\footnotetext{
14 Comunicación entre el intendente de Valdivia Manuel Montoya y Vicente Benavides. Valdivia, may. 5, 1819. ANH, Santiago de Chile, Chile, Fondo Ministerio de Guerra, volumen 52, foja 67.

15 Ídem.

${ }^{16}$ Correspondencia del virrey Pezuela dirigida a Vicente Benavides, Lima, mar. 3, 1820. ANH, Santiago de Chile, Chile, Fondo Ministerio de Guerra, volumen 52, foja 126.
} 
que cambió el cuerpo de dragones de la frontera por el regimiento de dragones de nueva creación, además de la disminución del número de compañías milicianas.

\section{a) Composición de la oficialidad de los cuerpos veteranos y milicianos}

La oficialidad concentraba a peninsulares y criollos, siendo estos últimos los más numerosos. Los indígenas no formaban parte de las tropas ni de la oficialidad puesto que su participación en la guerra fue a través de partidas comandadas por sus caciques o en las partidas de formación mixta -que se abordarán más adelante- las cuales no solo prestaban brazos para la guerra, sino que también diversos apoyos para el envío de comunicaciones y auxilios varios.

De la composición de la oficialidad conocemos algunos datos por el mismo Benavides quien, en el juicio en su contra, detallaba quiénes quedaron a cargo tras ser depuesto del mando luego de su derrota en la batalla de las Vegas de Saldias en octubre de 1821. En su declaración, dejaba en claro el origen de estos oficiales:

en la tierra quedaban algunos gefes y oficiales españoles que son como siguen, Coronel
[Juan Manuel] Pico = Teniente Coronel Carrero = Comandante de Esquadrón Miguel
Senosain = Ayudantes Antonio Yban, N. Ruti, N. Guerrero = Capitanes Antonio Servellon,
José Ignacio Savala = Tenientes Manuel Gilaver y Antonio Hijo.
Del país Coronel Vicente Bocardo = Comandantes de Esquadron Pedro Maldonado, Pedro
Pablo Villouta, Damasio Erquiñigo = Capitán Eusevio Torres a quien dejó encargado el
mando de la gente de toda la costa que no quiere obedecer al Carrero y otros cuyos nombres
en la actualidad no tiene presentes. ${ }^{17}$

La información presentada permite reconocer que, aunque existía una oficialidad peninsular, también había un importante componente criollo. Este fenómeno no era nuevo, en particular desde fines del siglo XVIII en América como demuestra el trabajo de Juan Marchena quien plantea que a inicios del siglo xIX el ejército de dotación contaba entre su oficialidad con un porcentaje importante de criollos: «la oficialidad criolla [...] inicia en la década de los setenta una escalada que le permitirá en los primeros diez años del siglo XIX, ser casi dos tercios de todo el ejército. El caso de los peninsulares sería exactamente el inverso» (Marchena 162) y Chile, a pesar de su condición periférica, no escapaba a ello: «el ejército colonial

\footnotetext{
${ }_{17}$ Causa criminal contra Vicente Benavides y otros, Santiago, feb. 14, 1822. ANH, Santiago de Chile, Chile, Fondo Ministerio de Guerra, volumen 52, foja 218.
} 
chileno estaba, a fines del siglo XVIII, prácticamente en su totalidad en manos criolla» (Ossa 2010: 431).

Dentro del componente criollo presente en la oficialidad realista, destaca Vicente Benavides quien estuvo al mando de las tropas durante los años de la «Guerra a Muerte». Proveniente de una familia «respetable pero empobrecida» (Barros Arana 2), Vicuña Mackena lo describía como:

un hombre de más de cuarenta años, alto, musculoso, de tez morena, rostro oval i abultado con mejillas prominentes, el pelo denso, grueso i oscuro, tipo, en fin, del mestizo indíjena [...] vestía siempre como paisano, con botas fuertes, poncho i un gran sombrero de paja o gorra de paño encarnado (Vicuña Mackenna 310-11).

Por la información recabada sobre Benavides, es posible considerarlo un criollo pobre que no pertenecía a la elite, por lo cual parece adecuado considerarlo un sujeto popular. ¿Cómo terminó un criollo pobre a cargo de las tropas realistas? Tal vez la respuesta puede encontrarse en el contexto bélico que abrió la posibilidad de ascenso a sujetos como Benavides.

\section{b) Vicente Benavides, un criollo pobre comandante de los ejércitos reales}

Vicente Benavides, originario de la provincia de Concepción, estuvo tempranamente vinculado a la guerra de independencia. Inicialmente, formó parte de las tropas revolucionarias en calidad de sargento, pero desertó de estas en 1814 uniéndose a las tropas realistas donde en pocos años obtuvo ascensos y reconocimientos por sus acciones de guerra. El primero de esos ascensos fue entregado por sus acciones en la batalla de Rancagua en octubre de 1814 cuando obtuvo el grado de subteniente de ejército. Posteriormente, en 1817 se le «nombra teniente de la Compañía de Granaderos del Batallón de Infantería Ligera de Concepción ", ${ }^{8}$ y a fines de ese mismo año se le reconoce el grado de capitán de infantería (Riquelme 121). En la batalla de Maipú en 1818 fue tomado prisionero por los patriotas y condenado a muerte, sentencia que fue ejecutada; sin embargo, milagrosamente quedó con vida y una vez recuperado de sus lesiones se presentó a los mismos que lo apresaron para ofrecerse como espía. Fue enviado al sur donde, lejos de cumplir la tarea encomendada, reorganizó en corto tiempo la movilización realista llegando a estar al mando de sus

\footnotetext{
${ }_{18}$ Nombramiento de Vicente Benavides como Teniente de la Compañía de Granaderos del Batallón de Infantería ligera de Concepción, Talcahuano, oct. 17, 1817. ANH, Santiago de Chile, Chile, Fondo Ministerio de Guerra, volumen 52, foja 9
} 
tropas en calidad de comandante de la Frontera. Es posible que su posición social y su accionar en el ejército favoreciera su vinculación tanto con la oficialidad militar (peninsular y criolla) como también con las parcialidades indígenas.

El contexto bélico que favoreció los ascensos de Benavides se intensificó durante la «Guerra a Muerte». La conformación de nuevos cuerpos armados fue fundamental para el control que logró tener sobre las tropas, pues le aseguró lealtades y apoyos mientras estuvo al mando. La documentación sugiere que Benavides, aprovechando el control que ostentaba, hacía nombramientos requeridos en el momento de la guerra, sin tener más aprobación que su propia voluntad como demuestran las palabras de algunos de sus compañeros. Un ejemplo de ello es el caso de José María Xaramillo quien al momento de la indagatoria en su contra declaró se encontraba junto a Benavides porque este «tratando [...] de reunir gente en Ralqui lo hizo alférez».19 A su vez, Mateo Maimeny al ser consultado por su relación con Benavides declaraba que fue capturado en mayo de 1820 y «haviendo llegado a Arauco se vio precisado a admitir la oferta [de Benavides] de hacerle cadete de dragones».20

El control que tenía Benavides no fue indiferente a los demás oficiales que pronto mostraron su disconformidad. Para evitar mayores problemas el intendente de Valdivia solicitó a Benavides abstenerse de nombrar nuevos oficiales:

en lo sucesivo no se (criaran) más oficiales en ese destino pues así me lo encarga generalmente el excelentísimo señor virrey del Perú y quando VM. considere algún individuo acreedor a esta gracia o digno de mayor ascenso por una acción distinguida me lo propondrá usted para yo hacerlo al excelentísimo señor virrey a fin de qué se le expida el despacho correspondiente si se le considera hace acreedor. ${ }^{21}$

A lo anterior, se suma la molestia que manifestó Benavides a Montoya cuando este encargó a otro oficial criollo, Pedro Briones de Maldonado, la creación de un nuevo cuerpo armado. Para evitar inconvenientes, Montoya escribió a Maldonado que suspendiera

${ }_{19}$ Causa criminal contra Vicente Benavides y otros, Santiago, feb. 14, 1822. ANH, Santiago de Chile, Chile, Fondo Ministerio de Guerra, volumen 52, foja 210.

${ }^{20}$ Causa criminal contra Vicente Benavides y otros, Santiago, feb. 14, 1822. ANH, Santiago de Chile, Chile, Fondo Ministerio de Guerra, volumen 52, foja 211.

${ }^{21}$ Comunicación entre el intendente de Valdivia Manuel Montoya y Vicente Benavides. Valdivia, oct. 17, 1819. ANH, Santiago de Chile, Chile, Fondo Ministerio de Guerra, volumen 52, foja 92. 
la diligencia de levantar el esquadrón que le había encargado con respecto a oponerse a ello el comandante de esa frontera don Vicente Benavides con quien debe usted ir de acuerdo como se lo tengo encargado dejándose de rivalidades que son tan perjudiciales. ${ }^{22}$

Los peninsulares tampoco escaparon a la molestia de Benavides que desilusionado por sentirse utilizado y despreciado por su condición de criollo cerraba el juicio en su contra expresando que:

\begin{abstract}
le quedaba el sentimiento de haver conocido tan tarde las máximas el carácter de los españoles que hacen la guerra en América que se sirven de los hijos del país para despreciarles luego que no los necesita: que ellos son preferidos en los empleos y mando de las tropas, y jamás hacen confianza de otro que no sea de ellos mismos. Que a pesar de los servicios que el confesamente les ha hecho siempre lo han desatendido y procurado sacrificarlo y que morirá con el dolor de no haver hecho vean al mundo con sus operaciones la iniqua conducta de los españoles en América, pues al fin le pagaron sus servicios y grandes compromisos sublevandosele el resto de ellos que quedaba a sus órdenes. 23
\end{abstract}

El descargo de Benavides demuestra que el contexto bélico que surgió por las guerras de independencia favoreció los ascensos y vinculaciones que criollos de clases bajas pudieron ostentar en las tropas realistas. Él mismo reconocía que los peninsulares eran «los preferidos en los empleos y mando de tropas» y esperó de sus acciones reconocimientos que nunca llegaron. De todos modos, este mismo contexto favoreció que Benavides pudiera tener el manejo de un importante número de tropas y apoyos dentro de estas e incluso despertara rencillas con sus compañeros de armas por sus decisiones, lo cual permite afirmar que el liderazgo de Benavides tenía una base de legitimación que probablemente surgió de los auxilios recibidos, los reconocimientos entregados y las batallas ganadas lo que le permitió ostentar el control de las tropas por largo tiempo.

\title{
4. Partidas indígenas y de formación mixta: el otro brazo del conflicto
}

Un aporte importante a la movilización realista lo hicieron las partidas indígenas y de formación mixta. Aun cuando actuaron en variadas ocasiones junto a las tropas regulares lo cierto es que su funcionamiento era autónomo y no subordinado a estas. Las partidas mencionadas fueron fundamentales para la mantención de la guerra en el territorio de la Araucanía, en especial las partidas indígenas que no solo

${ }^{22}$ Comunicación del intendente de Valdivia Manuel Montoya al Teniente coronel don Pedro Briones de Maldonado, Valdivia, dic. 24, 1819. ANH, Santiago de Chile, Chile, Fondo Ministerio de Guerra, volumen 52, foja 121.

${ }^{23}$ Causa criminal contra Vicente Benavides y otros, Santiago, feb. 21, 1822. ANH, Santiago de Chile, Chile, Fondo Ministerio de Guerra, volumen 52, foja 227. 
aportaban con brazos para la guerra, sino también apoyo en las comunicaciones y diversos auxilios. Durante el período analizado, se ha identificado dos partidas como las de mayor presencia e importancia: en las partidas indígenas las lideradas por el cacique Mariluan y en las de formación mixta las lideradas por los hermanos Pincheira.

\section{a) Partidas indígenas}

Las partidas indígenas, sin ser parte de las tropas regulares, funcionaron como apoyo a estas. La anterior distinción es de suma importancia pues su incorporación a la contienda debe entenderse en un contexto que considere al menos dos elementos: por un lado, el traslado de la guerra a su territorio que provocó una incorporación masiva al conflicto bajo sus propios intereses; por otro lado, que estas partidas se conformaban a partir de algún liderazgo, que en un contexto de guerra, no podía ser estable y permanente, sino que se adaptó a las necesidades del momento. Junto con ello, es importante considerar que se debe analizar a la sociedad mapuche no como un todo, sino como parcialidades «que se insertaron por opción u obligación a esta ruptura colonial» (Pairicán 75).

El escenario de la «Guerra a Muerte» fue particularmente impactante en la sociedad indígena, pues, aunque este enfrentamiento era parte del binomio patriotas versus realistas las parcialidades que se sumaron también tenían sus propios conflictos, en este caso, pugnas entre los liderazgos por el poder en el territorio, lo que muestra que, aunque muchas parcialidades se aliaran para luchar en nombre del rey, su vinculación obedecía a sus propios intereses. Como menciona Fernando Pairicán la sociedad indígena lejos de ser una sociedad sin historicidad era una sociedad «con permanentes pugnas, alianzas y contra-alianzas» (69), lo cual obligó a las autoridades de ambos bandos a negociar con ellas con el fin de obtener su apoyo y lealtad.

El primer reconocimiento de la actuación de estas partidas es posible rastrearlo en el ataque combinado de las fuerzas realistas en febrero de 1819: «el principal combate en que Mariluan y Mailwenu" comenzaron a inscribirse en la historia ocurrió el 19 de febrero de 1819. Ese día el fuerte Negrete fue atacado por los mapuche y las tropas encabezadas por monarquistas» (Pairicán 81). La estrategia utilizada en esta ocasión fue la que se mantuvo durante todo el período de la «Guerra a Muerte»: «mientras la alianza perduró, estos [los criollos] atacaban los puestos de combate 
'regular', mientras que los mapuches invadían los poblados criollos para incendiarlos» (Pairicán 81-82).

Esta estrategia resultaba exitosa pues favorecía el ataque por diferentes frentes lo cual en un comienzo fue difícil de repeler para los patriotas que pronto comprendieron que debían negociar con las parcialidades indígenas para lograr su apoyo o, al menos, que rompieran su alianza con los realistas. Como reconoce Pairicán:

\footnotetext{
fue la resistencia indígena en alianza con las montoneras monarquistas, lo que llevó a los líderes republicanos a crear una especie de «política indígena», que consistió básicamente en volver a los protocolos coloniales, es decir, parlamentar con los ñidolonko mapuche, pero bajo un nuevo marco ideológico derivado de las revoluciones de independencia (78).
}

No solo los patriotas llevaron adelante una «política indígena», sino también los realistas quienes mantuvieron las relaciones políticas que tradicionalmente se habían desarrollado entre autoridades hispanocriollas e indígenas, lo que obligó a pactar alianzas, llevar adelante negociaciones y hacer los agasajos necesarios para que ambas salieran beneficiadas. Crow y Ossa han demostrado que «más allá de la guerra, la negociación política estuvo muy presente durante estos años» (53) y que esta negociación era parte del accionar político de las comunidades «en el sentido de que actuaban a partir de la realidad concreta y con el horizonte puesto en el futuro» (53). Esta negociación y forma de vinculación tenía como base la forma de interaccion y negociación asentada durante las décadas anteriores basada en parlamentos y tratados.

Aunque no se conoce de algún parlamento entre 1819 y 1824 entre autoridades realistas y parcialidades indígenas, sí hubo una serie de acuerdos y, además, se sabe que los realistas recibían apoyo por parte de un número importante de parcialidades y que, a su vez, estaban constantemente enviando agasajos, entregando apoyo militar en caso que las parcialidades lo requiriesen para atacar a sus enemigos y poniendo al tanto a los caciques sobre las acciones a desarrollar.

Las comunicaciones entre las autoridades realistas muestran que existió una constante preocupación por obsequiar a los indígenas por los auxilios prestados durante la guerra. Entre los variados auxilios que enviaba el virrey Pezuela a Benavides en 1820 para sostener la guerra en la frontera, se preocupaba especialmente de enviar 
algunos artículos «que pueden servir para agasajar a esos naturales» 24 de los cuales el virrey estaba profundamente agradecido por «el laudable entusiasmo con que perseveran en nuestro auxilio».25 Un año más tarde, desde Chiloé, el gobernador de la isla comunicaba a Benavides las diversas atenciones realizadas a los caciques con el objetivo de que estos convocaran a más de los suyos:

\begin{abstract}
los caciques don Ignacio Marileu y Don Pasqual Antinao han sido obsequiados de un modo que han satisfecho de la franqueza con que se les ha tratado. Han hablado (con) alguno de los caciques de esta provincia: han visto las (tropas) y los castillos: les he oído su parla: les he conbidado conmigo a la mesa y últimamente entre los regalos que se les (dan) y el gasto que han hecho manteniéndolos en una casa no bajará de ciento sinquenta por el que han causado todo bien empleado si como me han ofrecido coadyubar con los demás caciques al sostén de la guerra. ${ }^{26}$
\end{abstract}

Otro aspecto que realistas - y patriotas - debían asegurar a los indígenas era el apoyo militar que estos solicitasen para hacer frente a sus enemigos. Manuel Montoya se quejaba con Benavides sobre esta situación, pues incluso tuvo que ceder ante la petición de los indígenas de entregarles soldados cuando él mismo quedaba expuesto: «el cacique de este Butalmapu que ha venido a esta plaza se ha empeñado fuertemente sobre llevar tropa pero no me es posible el dársela porque usted sabe los muchos castillos del puerto y tengo todos guarnecidos».27 A pesar de la queja expuesta, Montoya tuvo que ceder a la petición del cacique: «iran con los indios 12 oficiales por ahora con igual número de soldados, municiones, algunos efectos para vestir (su) benemerita tropa». 28

Además de facilitar tropa a los caciques aliados, los ataques que se efectuaban en conjunto no solo eran aprobados por quienes estaban a cargo de la tropa regular, sino que los caciques estaban al tanto y decidían cuándo actuar. Así quedó de manifiesto en 1824 cuando Mariluan no se involucró en ayuda de su aliado y amigo, el jefe realista Juan Manuel Pico quien se encontraba en sus tierras cuando fue asesinado por los patriotas. Pairicán sostiene que «es difícil pensar que los republicanos pudieran ingresar a las tierras de Mariluan sin ser detectados. No sucedió en los tiempos más

\footnotetext{
${ }_{24}$ Comunicación del virrey del Perú Joaquín de la Pezuela a Vicente Benavides, Lima, may. 3, 1820. ANH, Santiago de Chile, Chile, Fondo Ministerio de Guerra, volumen 52, foja 130.

25 Ídem.

${ }^{26}$ Comunicación del gobernador de Chiloé Antonio Quintanilla con Vicente Benavides, San Carlos de Chiloé, jul. 29, 1821. ANH, Santiago de Chile, Chile, Fondo Ministerio de Guerra, volumen 52, foja 140.

${ }_{27}$ Comunicación del intendente de Valdivia Manuel Montoya a Vicente Benavides, Valdivia, dic. 6, 1819. ANH, Santiago de Chile, Chile, Fondo Ministerio de Guerra, volumen 52, foja 106.

28 Ídem.
} 
álgidos de la guerra, menos podría suceder con los diálogos bilaterales» (Pairicán 126), por lo cual infiere que Mariluan actuó según las necesidades políticas de ese momento ya que estaba en negociaciones con los patriotas.

Es justamente el cacique Mariluan el principal liderazgo que surgió durante de la «Guerra a Muerte». Coincidimos con lo planteado por Pairicán respecto a este cacique, ya que evidencia la existencia de una agencia indígena que aprovechó el contexto de la guerra para afianzar su poder o dirimir sus propios conflictos, por lo cual era poco probable que su alianza con el bando realista hubiese sido solo por la influencia de los franciscanos o por su «odio al blanco» (91). Aunque la guerra le permitió acceder a recursos, armas y hombres, Mariluan también se vio afectado por las acciones bélicas, ya que en un combate a fines de 1819 fue gravamente herido lo que además fue un duro golpe para los realistas que anhelaban su pronta recuperación, tal como expresaba Montoya a Briones de Maldonado: «entiendo igualmente el golpe que sufrió en el combate el cacique Mariluan y el mocetón que celebraré se restablezca lo más pronto». 29

La participación de Mariluan fue fundamental pues contaba con una importante capacidad de movilización que lo hacía temible. Además, durante los primeros años de la «Guerra a Muerte» el creciente liderazgo de otro cacique, Mailwenu", en apoyo a los realistas permitía una convocatoria de brazos aún mayor. Aunque resulta dificultoso estimar la cantidad de hombres que movilizaban estas partidas, algunas fuentes citadas por Pairicán mencionan: «que este líder [Mariluan] era uno de los más fuertes junto a Mailwenu“" (92), unidos, componían un bloque hegemónico difícil de resquebrajar. Para pelear contra ellos, «tenían que unirse varias reducciones. Si una reducción los atacaba con quinientos hombres, ellos le oponían mil» (Pairicán 92). Más allá de la realidad de estos números, lo cierto es que Mariluan tenía una capacidad movilizadora enorme que lo hacía un aliado poderoso y con el que debía negociarse, en especial porque tenía influjo en un amplio territorio. Aunque los realistas reconocieron esto más tempranamente, los patriotas pronto comprendieron que para tener la correlación de fuerzas a su favor requerían negociar con Mariluan.

29 Comunicación del intendente de Valdivia Manuel Montoya al teniente coronel don Pedro Briones de Maldonado, Valdivia, dic. 24, 1819. ANH, Santiago de Chile, Chile, Fondo Ministerio de Guerra, volumen 52, foja 121. 
Por lo tanto, las alianzas indígenas eran importantes pues de alguna manera definían la relación de fuerzas en un escenario en donde era importante contar con contingentes. Rodrigo Araya menciona que Mariluan, aunque olvidado por la historiografía, además de su gran capacidad movilizadora llevaba adelante «el antiguo proyecto político de los caciques gobernadores que consistió en dotar a la Araucanía de un mínimo orden que le permitiera desarrollarse en armonía junto a sus vecinos hispanocriollos» (Araya 2), para lo cual recurrió tanto a las armas como a la diplomacia.

En efecto, Mariluan aparece como uno de los caciques más activos en las acciones de los realistas, y también muy solicitado a la hora de negociar. Así puede leerse en diversas comunicaciones de autoridades patriotas que comentaban el estado de las conversaciones con este cacique. Juan de Dios Rivera, intendente de la Provincia de Concepción, daba cuenta lo dificultoso que fue lograr un acuerdo con él, ya que manejó las relaciones según las circunstancias y, por tanto, no tenía un postura única e inmutable:

Lo transcribo a usted para su inteligencia i gobierno; previniéndole que ya es de necesidad exijir de Mariloan su final resolución al tratado de avenencia o aserle entender que las hostilidades deben romperse necesariamente si continua en aquella irresolución; cuya conducta en todo representa el carácter de malisiosa; i consolo el objeto de ganar el tiempo. ${ }^{30}$

Como se mencionó anteriormente, las negociaciones con las autoridades eran una práctica de larga data en el horizonte indígena. Durante la «Guerra a Muerte» los indígenas utilizaron estas prácticas -arraigadas en la cultura colonial monárquica de fines del siglo XVIII- para generar alianzas, conseguir lo que necesitaban e intentar resolver sus propios conflictos. Por lo tanto, basaron sus relaciones en prácticas que no eran nuevas, sino que eran formas de acción política conocidas y legitimadas.

Un claro ejemplo de esto es la firma del Parlamento de Tapihue a inicios de 1825 donde Mariluan, luego de meses de negociaciones, pactó con los patriotas como «gobernador de 14 reducciones» comprometiéndose a «hacer cesar todos los males que han aflijido a la República en catorce años de consecutiva guerra» (Tellez et al. 187). Se comprometía además a marchar contra quienes se mantenían defendiendo el

${ }_{30}$ Comunicación del intendente de Concepción Juan de Dios Rivera, Concepción, ene. 7, 1824. ANH, Santiago de Chile, Chile, Fondo Intendencia de Concepción, volumen 75, s/f. 
realismo, disponiendo que «estará pronto con todas sus fuerzas para unirse a las del Estado si fuese necesario marchar contra los rebeldes de Pincheira, y sus aliados de ultra cordillera» (Tellez et al. 189). Los pactos firmados dan cuenta de la forma de sellar acuerdos propia de los parlamentos que ahora Mariluan ponía en práctica con las nuevas autoridades comprometiendo estos últimos los agasajos correspondientes, así como también los ritos ceremoniales que daban por ratificada la unión.

En síntesis, las partidas indígenas, en particular las lideradas por Mariluan, fueron fundamentales apoyos a la hora de definir la correlación de fuerzas en la guerra, tanto así que cuando Mariluan no apoyó a Juan Manuel Pico, este cayó y terminó asesinado. En este sentido, Pairicán menciona algo que no deja de ser notable y es que Mariluan prefirió mantener su estrategia política de paz antes que cumplir con la tradición.

Tras la muerte de Pico en 1824 y los pactos de Mariluan con las autoridades de gobierno en 1825 la Guerra a Muerte dejó de ser tal y los restos dispersos de los realistas se refugiaron con las partidas de formación mixta en la cordillera las cuales se mantuvieron movilizadas en el espacio cordillerano y en las pampas hasta 1832.

\section{b) Partidas de formación mixta}

Las partidas de formación mixta, compuestas por indígenas e hispanocriollos, fueron el otro refuerzo importante para las tropas regulares realistas. Sin duda, las partidas lideradas por los hermanos Pincheira fueron las más importantes, no solo por su presencia en estos primeros momentos de la guerra, sino porque ampliaron su espacio de movilización hacia las pampas y lograron mantenerse movilizadas hasta 1832. Según ha mostrado Ana María Contador, los hermanos Pincheira eran hijos de Martín Pincheira, un inquilino de la hacienda de Lloycalemu propiedad de Miguel Zañartu. En aquel lugar habrían nacido sus hijos: Antonio, Santos, Pablo y José Antonio y dos mujeres. (Contador 146). Durante la «Guerra a Muerte» el liderazgo de estas partidas estaba en manos de Antonio, el mayor.

La actuación de Antonio Pincheira en defensa del realismo es bastante temprana. En agosto de 1817 se comunicaba desde Chillán al Director Supremo de Chile, Bernardo O'Higgins que existían partidas enemigas y que estas aumentaban cada día más y que «en las montañas [...] anda otra partida de cinco fusileros y alguna 
milicia comandada por Mariano Alarcón y Antonio Pincheira». ${ }^{3^{1}}$ En octubre de ese mismo año, se comunicaba la aparición de «bandidos» que atacaban las haciendas de los patriotas en la Villa de San Carlos. En este ataque el «pérfido [...] e infame traidor Pincheyra con trescientos y más individuos que formaban una gavilla de bandidos [...] arrasaban las haciendas salteando y degollando a su arbitrio a los decididos a nuestra sagrada causa». $3^{2} \mathrm{Al}$ menos en este primer momento, Antonio Pincheira defendía la causa del rey, pero la movilización que se mantuvo después de la «Guerra a Muerte» luego de la muerte de Antonio (1823), parece haber mutado y el uso del realismo podría tener otros significantes. Además de la temprana vinculación de Pincheira con la causa realista, también se mostraba que en sus ataques contaba con aliados indígenas: «el enemigo se ha tomado la Villa de San Carlos [...] y que este enemigo es Pincheyra con indios que han salido por el voquete de Alico».33

La presencia indígena en estas partidas era considerable. Las alianzas que las parcialidades cordilleranas hicieron con Pincheira no eran muy diferentes respecto de las alianzas de las parcialidades del sur del Biobío con las tropas regulares, ya que respondían principalmente a conflictos anteriores entre los caciques. Una de las alianzas más importantes fue la que Pincheira logró con el cacique Martín Toriano. Esta alianza significó que Toriano constantemente aportara hombres a las partidas con el fin de tener apoyo cuando tuviese que defenderse o atacar a su principal rival, el cacique Luis Melipan, quien tempranamente estuvo aliado con los patriotas: «don Luis, auxiliado por los independentistas con víveres y operadores de armas de fuego, atacó a Toriano, causándole unas doscientas bajas» (Villar y Jiménez 176). Por su parte, Toriano aliado a los realistas, aportaba brazos para los ataques: «como aliado de los montoneros [...], conjuntamente con otros caciques, [Toriano] aportó 400 indígenas a una incursión de Pablo Pincheira» (Villar y Jiménez 172), con el fin de tener apoyo cuando tuviese que defenderse o atacar a Melipan. 34

\footnotetext{
${ }^{31}$ Pedro Arriagada, Comunicación de Pedro Arriagada al Director Supremo, Chillán, ago. 1, 1817. ANH, Santiago de Chile, Chile, Fondo Ministerio de Guerra, volumen 23, foja 201.

32 Comunicación a Bernardo O’Higgins, Chillán , dic. 21, 1817. ANH, Santiago de Chile, Chile, Fondo Ministerio de Guerra, volumen 23, foja 225.

33 Comunicación de Pedro Nolasco Sepulbeda al Señor Gobernador de la Villa de Cauquenes, Chillán, dic. 21, 1817. ANH, Santiago de Chile, Chile, Fondo Ministerio de Guerra, volumen 23, foja 283.

34 Para seguir este conflicto véase: Daniel Villar y Juan Francisco Jiménez. «Conflicto, poder y justicia. El cacique Martín Toriano en la cordillera y las pampas (1818-1832)». Conflicto, poder y justicia en la frontera bonaerense, 1818-1832. Daniel Villar, Juan Francisco Jiménez y Silvia Ratto. (Bahía Blanca \&
} 
El componente hispanocriollo de las partidas era de diverso origen social. Durante la Guerra a Muerte es posible reconocer el apoyo de importantes hacendados de la zona como Manuel Vallejo y Miguel Zañartu, así como también de algunos religiosos como el mercedario José Antonio Gómez. A medida que avanzaba la guerra, estas partidas fueron refugio de oficiales y tropa de los cuerpos regulares como Vicente Bocardo y Miguel Senosain así como también se unieron a ella sujetos comunes y corrientes provenientes de lugares cercanos.

La actuación de estas partidas se concentraba al norte del Biobío y en áreas más cercanas a la cordillera como Chillán, Parral, San Carlos y Linares. Esto debido a que sus campamentos se encontraban emplazados en las montañas de Cato cercano al Voquete de Alico, lugar estratégico que permitía tanto el desplazamiento directo hacia estos puntos como un cruce allende la cordillera donde los Pincheira comenzaron a tener aliados. Aunque estas partidas lograron una importante movilización de fuerzas, lo cierto es que parecen haber sido secundarias en la movilización que se concentró mayormente en las cercanías del Biobío.

El número de personas que componían estas partidas fue variable en el tiempo. Aunque es difícil determinar un número exacto, Ana María Contador menciona que se pueden hacer estimaciones a través de las fuentes concluyendo que en este primer momento estas partidas movilizaban un aproximado de entre doscientos a cuatrocientos hombres (Contador 149-50-51), cifra que parece verificarse a través de las fuentes que en general dan cuenta de entre 200 a 400 hombres al menos en los primeros años de movilización tal como vemos en una comunicación a Bernardo O’Higgins en que se mencionaba que «el pérfido, iniquo, infame traidor Antonio Pincheyra con trescientos y más individuos formaban una gavilla de bandidos» 35 que atacaban en Chillán y San Carlos.

Ahora bien, la estrategia de ataque de estas partidas era muy similar a las partidas indígenas en tanto no convocaban el enfrentamiento directo de tropas, sino más bien la entrada sin previo aviso a los pueblos que tenían como objetivo. Pérez

Santa Rosa: Departamento de Humanidades de la Universidad Nacional del Sur y Facultad de Ciencias Humanas de la Universidad Nacional de La Pampa, 2003), 131-286.

35 Comunicación a Bernardo O’Higgins, Chillán, dic. 21, 1817. ANH, Santiago de Chile, Chile, Fondo Ministerio de Guerra, volumen 23, foja 225. 
menciona que su estrategia «consistió en la formación de pequeñas partidas que atacaban rápidamente sin presentar nunca batalla directa, o por lo menos como lo hacían los ejércitos regulares, disolviéndose después de lograr su objetivo» (71). El mismo autor elaboró una tabla para contrastar entre lo que denomina fuerza total de estas partidas que implicarían el número de individuos que las componen y la cantidad de ellos que participan en los ataques, a lo que denomina partidas. La tabla 4 da cuenta de la conformación que tuvieron y que mantuvieron en el tiempo estas partidas.

Tabla 4

Comparación numérica de la montonera y las partidas

\begin{tabular}{|c|c|c|}
\hline Año & Montonera & Partidas \\
\hline 1822 & 200 & $60-100$ \\
\hline 1823 & 400 & 250 \\
\hline 1825 & 600 & 200 \\
\hline 1826 & $200-500$ & $10-150$ \\
\hline
\end{tabular}

Tabla elaborada por Manuel Pérez, «La otra cara de la montonera: un acercamiento a la política popular de la experiencia pincheirina. La Frontera, 1817-1832», Tesis de Magíster en Historia, Santiago de Chile: Universidad de Santiago de Chile, 2018, 71.

La temprana vinculación de los Pincheira con parcialidades indígenas permitió desarrollar una forma de ataque que fácilmente se confundía con incursiones indígenas. Juan Francisco Jiménez plantea que esta vinculación entregó a estas partidas de formación mixta una forma de hacer la guerra que se condice con lo relatado por Pérez en cuanto a su forma de ataque, además que: «al combatir en formaciones mixtas [...] en las que se combinaban las culturas militares de sus componentes los mapuche crearon un nuevo estilo de hacer la guerra» (66) en donde las armas de fuego terminaron por ser de gran utilidad y donde la caballería indígena era muy apetecida. Lo anterior quedó demostrado no solo durante la «Guerra a Muerte», sino también en los años siguientes en donde la capacidad de ataque que lograron estas partidas de formación mixta les permitió ampliar su espacio de movilización considerablemente. Sin duda, el escenario bélico contribuyó a la formación de estas alianzas entre criollos e indígenas, las cuales luego de sellado el conflicto realistas versus patriotas, siguieron movilizadas e involucradas en los conflictos entre las parcialidades para obtener respaldo tanto económico como militar.

Tanto las partidas indígenas como las de formación mixta, a pesar de estar en constante comunicación y de tener entre sus filas a las tropas dispersas, mantuvieron cierta autonomía respecto de las tropas regulares. De todos modos, la combinación de 
fuerzas logró mantener una importante población movilizada a favor de la causa realista durante todo el período de la Guerra a Muerte.

\section{Conclusión}

El presente artículo ha demostrado que durante la Guerra a Muerte la movilización realista estuvo conformada por variados brazos armados: cuerpos veteranos y milicianos existentes y de nueva formación junto al importante aporte de las partidas indígenas y de formación mixta. La diversidad de cuerpos armados junto a las variadas estrategias utilizadas, permitieron que la movilización realista por momentos lograra importantes ventajas en la guerra, en particular cuando contaba con un apoyo más patente de las parcialidades indígenas al sur del Biobío.

En los cuerpos veteranos, la reorganización llevada adelante por un criollo pobre como Vicente Benavides permitió la creación de diversas alianzas con parcialidades indígenas, así como también la movilidad dentro de la tropa de soldados y oficiales en los cuerpos de nueva creación que Benavides impulsó para llevar adelante la movilización. El mismo Benavides, gracias al contexto bélico, ascendió rápidamente convirtiéndose en comandante de los ejércitos reales. En este sentido, el realismo al que adhieren Benavides y otros sujetos les fue beneficioso en algunos momentos de la guerra obteniendo ganancias junto con la constante promesa de las autoridades de premios futuros por sus acciones. Estos beneficios a los que accedieron sujetos como Benavides no surgieron como prácticas nuevas en el contexto bélico, sino que era una puesta en práctica de diferentes mecanismos conocidos que les permitieran acceder a mejores posiciones. Estos mecanismos eran la negociación con los indígenas, por ejemplo, que Benavides llevó adelante para conseguir aliados en la guerra siguiendo las tradiciones de agasajos y negociaciones con los caciques, así como también sus acciones en la guerra, las que constantemente ponía en conocimiento de otras autoridades para lograr reconocimientos y ascensos. Ahora bien, aunque Benavides parece utilizar los beneficios de la guerra a su favor y tener un uso más bien utilitario de su vinculación realista lo cierto es que, aunque luchó en ambos bandos en diferentes momentos, sus acciones tendían a estar mayormente vinculadas al realismo, incluso en los momentos más álgidos de la guerra. Sus cuestionamientos a la causa estaban más vinculados a los peninsulares con quienes tuvo roces que a la defensa del rey en sí misma de la que nunca renegó. 
Por otra parte, la vinculación al realismo también permitió que las parcialidades indígenas se involucraran en el conflicto obteniendo de los realistas apoyos, agasajos y consideraciones propias de las negociaciones entre autoridades, lo cual facilitó el tener acceso a armas, tropas y municiones que utilizaban para dirimir sus propios conflictos intraétnicos como fue el caso de los caciques Mariluan y Toriano. En este sentido, resulta importante destacar que estos liderazgos se unieron a la lucha realista no por ingenuidad ni engaño, sino por sus propios intereses, llevando adelante una serie de prácticas ya instaladas de negociación y acuerdos que desarrollaban desde tiempos monárquicos y que no hicieron más que seguir siendo la forma de relación frente a esta nueva coyuntura que se abría.

Por último, las partidas de formación mixta lograron mantener una movilización mucho más autónoma, a pesar de su temprana vinculación al realismo. Combinaron diversas estrategias para hacer la guerra y gracias a sus refugios en la cordillera lograron mantenerse movilizadas por mucho tiempo más. El liderazgo de un sujeto popular como Antonio Pincheira y sus hermanos, oriundos de la zona, favoreció las alianzas y apoyo que se prestó al realismo por parte de las parcialidades indígenas cordilleranas.

Esta diversidad de brazos armados da cuenta de las alianzas multiétnicas que permitieron la defensa del realismo en la zona de la Araucanía. A su vez, evidencian que el realismo fue parte de la acción política de los sujetos que en pos de invocar al rey lograron en algunos casos ascensos y reconocimientos, así como también apoyos para enfrentar sus propios conflictos. Aunque la participación en la guerra respondía a sus propios intereses, la defensa del realismo se asentaba no solo en estos intereses, sino también en prácticas conocidas.

El contexto propio de la guerra favoreció el ingreso masivo de las parcialidades indígenas al conflicto al trasladar el escenario bélico a la Araucanía, así como también facilitó la aparición de liderazgos populares que influyeron y movilizaron a otros en pos de sus objetivos en una movilización que tendría su apogeo durante la Guerra a Muerte pero que se mantendrá movilizada invocando el nombre del rey por muchos años más.

Aunque el presente trabajo busca ser un aporte al estudio de los sujetos que se movilizaron en defensa del realismo aún queda mucho por hacer. La movilización 
realista en el sur de Chile no culminó con la Guerra a Muerte. En 1825 se inaugura una nueva etapa de movilizaciones que no solo van a desarrollarse en el actual territorio chileno, sino que van a ampliar su radio de acción hacia la pampa argentina con nuevos aliados, nuevas formas de acción y negociaciones que se espera analizar más adelante a la luz de estas renovaciones historiográficas comentadas al inicio del trabajo. A su vez, muchos otros temas quedan pendientes de conocer y sería interesante pensarlos para futuras investigaciones siendo uno de ellos la participación femenina en esta movilización realista ¿qué rol cumplían las mujeres en esta coyuntura? ¿qué apoyos prestaban a la guerra? Preliminarmente hemos encontrado algunos rastros sobre estos temas, como acusaciones contra algunas mujeres por dar refugio a los enemigos y también por desempeñarse como espías. Aunque no es tema de este trabajo, la participación de las mujeres en la guerra resulta una arista de análisis interesante $-\mathrm{y}$ a la vez difícil- de abordar.

\section{Obras citadas}

\subsection{Fuentes}

\subsubsection{Archivos}

Archivo Nacional Histórico de Chile (ANH), Santiago de Chile, Chile, Fondo Ministerio de Guerra, volumen 23.

Archivo Nacional Histórico de Chile (ANH), Santiago de Chile, Chile, Fondo Ministerio de Guerra, volumen 52.

Archivo Nacional Histórico de Chile (ANH), Santiago de Chile, Chile, Fondo Intendencia de Concepción, volumen 75.

\subsubsection{Documentos impresos}

Feliú Cruz, Guillermo. Colección de Antiguos periódicos chilenos, Santiago de Chile: Imprenta Universitaria Valenzuela Basterrica y Cía, 1954.

\subsection{Bibliografía}

Araya, Rodrigo. «Mariluán, el lonko olvidado de la Guerra a Muerte», Cyber Humanitatis 27 (2003).

Barros Arana, Diego. Estudios Históricos sobre Vicente Benavides i las campañas del sur.1818-1822. Santiago de Chile: Imprenta de Julio Belin i Compañía, 1850.

Bengoa, José. Historia del pueblo mapuche (siglos XIX y XX). Santiago de Chile: Ediciones Sur, 1996.

Bonilla, Heraclio y Karen Spalding (comps.). La independencia del Perú. Lima: Instituto de Estudios Peruanos, 1973.

Contador, Ana María. Los Pincheira, un caso de bandidaje social. Chile 1817-1832. Santiago de Chile: Editorial Bravo y Allende, 1998. 
Crow, Joanna y Juan Luis Ossa Santa Cruz. «'¿Indios seducidos?' Participación político-Militar De Los Mapuche Durante La Restauración De Fernando VII. Chile, 1814-1825». Revista Universitaria De Historia Militar 15 (2018): 39-58. https://ruhm.es/index.php/RUHM/article/view/506.

De Almozara, Francisco, «El Ejército de Chile. De la Capitanía General a la joven República (1603-1823)», Tesis de Doctorado en Historia, Madrid: Universidad Carlos III, 2015 .

Echeverri, Marcela. Esclavos e indígenas realistas en la Era de la Revolución. Reforma, revolución y realismo en los Andes septentrionales, 1780-1825. Bogotá: Universidad de los Andes, Ediciones Uniandes: Banco de la República de Colombia, 2018.

Echeverri, Marcela. «Monarchy, Empire, and Popular Politics in the Atlantic Age of Revolutions», Varia Historia 67 (2019): 15-35.

Fradkin, Raúl (ed.). ¿Y el pueblo dónde está? Contribuciones para una historia popular de la Revolución de Independencia en el Río de la Plata. Buenos Aires: Prometeo libros, 2015.

Gazmuri, Cristian. La historiografía chilena (1842-1970) Tomo I (1824-1920). Santiago de Chile: Centro de investigaciones Diego Barros Arana, 2006.

Jiménez, Juan Francisco. «De malares y armas de fuego. Guerras intra-étnicas y transformaciones en la tecnología bélica en Araucanía y las Pampas (18181830)». Relaciones inter-étnicas en el Sur bonaerense 1810-1830. Ed. Daniel Villar. Bahía Blanca: Departamento de Humanidades, Universidad Nacional del Sur/IEHS, Universidad Nacional del Centro de la Provincia de Buenos Aires, 1998. 47-78.

León, Leonardo. Ni patriotas ni realistas. El bajo pueblo durante la independencia de Chile. 1810-1822. Santiago de Chile: Centro de Investigaciones Diego Barros Arana, 2011.

Manara, Carla. «Movilización en las fronteras. Los Pincheira y el último intento de reconquista hispana en el sur americano (1818-1832)», Sociedades de paisajes áridos y semiáridos. 2 (2010): 39-60.

Marchena, Juan. Ejército y milicias en el mundo colonial americano. Madrid: Mapfre, 1992.

Méndez, Cecilia. La República Plebeya: Huanta y la formación del Estado peruano 1820-1850. Perú: Instituto de Estudios Peruanos, 2014.

Ossa, Juan Luis. «La criollización de un Ejército periférico, Chile, 1768-1810», Historia. 43 (2010): 413-448.

Ossa, Juan Luis. «The Army of the Andes: Chilean and Rioplatense Politics in an Age of Military Organization, 1814-1817», Journal of Latin American Studies. 46 (2014): 29-58.

Pairicán, Fernando, «Toqui: la resistencia a la ocupación de la Araucanía (1818-1861)», Tesis de Doctorado en Historia, Universidad de Santiago de Chile, Santiago de Chile: Universidad de Santiago de Chile, 2019.

Pérez Manuel, «Huasos, desertores y ladrones: la montonera de los hermanos Pincheira y la construcción de un caudillismo de base popular, 1817-1832», ", Tesis de Licenciatura en Historia, Santiago de Chile: Universidad Alberto 
Hurtado, 2014

Pérez Manuel, «La otra cara de la montonera: un acercamiento a la política popular de la experiencia pincheirina. La Frontera, 1817-1832», Tesis de Magíster en Historia, Santiago de Chile: Universidad de Santiago de Chile, 2018.

Pinto, Jorge. La formación del Estado y la nación y el pueblo mapuche. De la inclusión a la exclusión. Santiago: Dirección de Bibliotecas, Archivos y Museos, 2003.

Pinto, Julio y Valdivia, Verónica. ¿Chilenos todos? La construcción social de la nación (1810-1840). Santiago de Chile: LOM Ediciones, 2009.

Riquelme, Emilia, «Vicente Benavides ¿bandido realista?», Bicentenario. Revista de Historia de Chile y América. 1 (2017): 113-139.

Téllez , Eduardo, et al. «El tratado de Tapihue entre ciertos linajes mapuches y el Gobierno de Chile [1825]», Cuadernos de historia. 35 (2011): 169-190.

Villar, Daniel y Juan Francisco Jiménez. «Conflicto, poder y justicia. El cacique Martín Toriano en la cordillera y las pampas (1818-1832)». Conflicto, poder y justicia en la frontera bonaerense, 1818-1832. Daniel Villar, Juan Francisco Jiménez y Silvia Ratto. Bahía Blanca \& Santa Rosa: Departamento de Humanidades de la Universidad Nacional del Sur y Facultad de Ciencias Humanas de la Universidad Nacional de La Pampa, 2003. 131-286.

Vicuña Mackenna, Benjamín. La Guerra a Muerte. Memorias sobre las últimas campañas de la independencia de Chile. 1819-1824. Santiago de Chile

: Imprenta Nacional, 1868. 